\title{
Interprofessioneel assessment, een goede methode van beoordelen?
}

\author{
C.H.Z. Kuiper, J.A.J. Borghouts
}

\section{Samenvatting}

Inleiding: Dit artikel beschrijft de praktische uitwerking van assessmentvormen binnen competentiegericht onderwijs (CGO).

Methode: Het assessment werd toegepast bij hbo-studenten die, vanuit verschillende studierichtingen, een differentiatie volgden op het vlak van arbeid en gezondheid. In de literatuur wordt aangegeven dat gedrag en de resultaten daarvan in meerdere situaties beoordeeld moeten worden. Er werd daarom gekozen voor een expert-assessment en een portfolio assessment, omdat deze assessmentvormen lijken te passen bij de te verwerven competenties.

Beschouwing: Ofschoon er nog geen 'harde' resultaten beschikbaar zijn, is de eerste indruk dat de combinatie van zowel portfolio als assessment door de studenten en de beoordelaars als prettig wordt ervaren. Gesteund door resultaten uit de literatuur pleit dit voor de beoordeling van concreet gedrag in combinatie met een concreet resultaat. Hiervoor lijkt de combinatie van een portfolio-assessment en een (expert-) assessment een goede methode te zijn. (Kuiper CHZ, Borghouts JAJ. Interprofessioneel assessment, een goede methode van beoordelen? Tijdschrift voor Medisch Onderwijs 2005;24(3):138-146.)

\section{Inleiding}

Het gebruik van assessments bij competentiegericht onderwijs (CGO) houdt het hoger gezondheidszorg onderwijs (HGZO) in Nederland bezig. Dit bleek o.a. op het HGZO-congres 2004, waar verschillende presentaties en workshops aan dit fenomeen gewijd werden. Een van de lastige aspecten van CGO is het ontwerpen van assessmentvormen die recht doen aan de complexiteit van competenties, om nog maar te zwijgen over de tijd en geld die hierin geïnvesteerd moeten worden. ${ }^{1}$

Dit artikel is bedoeld om te schetsen hoe assessmentvormen ontwikkeld zijn voor het CGO van de Kenniskring Arbeid en Gezondheid (KAG). De KAG is een onderdeel van de Hogeschool Rotterdam en richt zich op professionals die werken op het gebied van de preventie van en de reintegratie, behandeling of begeleiding van (groepen) personen met arbeidsgerelateerde aandoeningen. Dit is een complex maatschappelijk vraagstuk dat niet door één discipline benaderd kan worden. In dit kader biedt de KAG studenten ergotherapie, fysiotherapie, maatschappelijk werk, personeel en arbeid, en verpleegkunde in de laatste fase van hun opleiding de mogelijkheid om deel te nemen aan een differentiatie. Deze differentiatiefase duurt twee kwartalen, waarin diverse werkvormen worden aangeboden op het gebied van visieontwikkeling, evidence based practice en ARBO-theorie en -vaardigheden. Daarnaast wordt een concreet project uitgevoerd. Studenten wordt de mogelijkheid geboden om competenties te verwerven binnen het domein van arbeid en gezondheid.

Dit artikel beschrijft de wijze waarop assessment in de opleiding is vormgegeven en beoogt derhalve uitsluitend een voorbeeld te geven van de mogelijkheid van implementatie van dit soort beoordelingen in het hoger beroepsonderwijs. Er 
is nog onvoldoende ervaring met de methode om resultaten te presenteren.

\section{Gebruikte begrippen}

\section{Competentie}

Onder competentie wordt in dit artikel verstaan een onderliggend vermogen om taken in de beroepspraktijk adequaat te verrichten. ${ }^{1}$ Een competent persoon is binnen een bepaalde situatie (context) en in een bepaalde functie (functioneringsdomein) in staat te kiezen uit een reeks beschikbare en geschikte handelingen en, gebruikmakend van kenmerkende hulpmiddelen, in staat een bepaalde taak of opdracht uit te voeren en een bepaald eindresultaat te bereiken. Het gedrag en het resultaat dienen beide waarneembaar te zijn en meetbaar met behulp van bepaalde indicatoren.

Sinds enkele jaren is binnen het hoger beroepsonderwijs het begrip 'competentie' niet meer weg te denken. Zoals bij de meeste nieuwe ontwikkelingen in het hoger onderwijs is er rondom het competentiebegrip bij herhaling sprake van een Babylonische spraakverwarring. Het begrip competentie wordt op uiteenlopende wijze geïnterpreteerd en uitgewerkt. ${ }^{2}$ Een groot aantal auteurs heeft een omschrijving gegeven van het begrip 'competentie'. In bijna alle omschrijvingen wordt impliciet of expliciet verwezen naar taakuitvoering met specifieke eisen vanuit de omgeving. ${ }^{3-6}$ Kuiper en Lemette ${ }^{7}$ voegen hieraan toe dat het reageren op die eisen, consistent, herhaalbaar en generaliseerbaar dient te zijn.

Jansen en Weisfelt ${ }^{8}$ waarschuwen dat een competentiebenadering ten onrechte frequent wordt geassocieerd met een persoonsgebonden benadering. Bij een competentiegerichte benadering wordt het vertrekpunt echter gevormd door eisen die een organisatie of de samenleving aan een persoon stelt in termen van gedrag en resultaat. Steeds wisselende eisen uit de omgeving vormen het vertrekpunt, niet de persoon. Maar steeds weer inspelen op

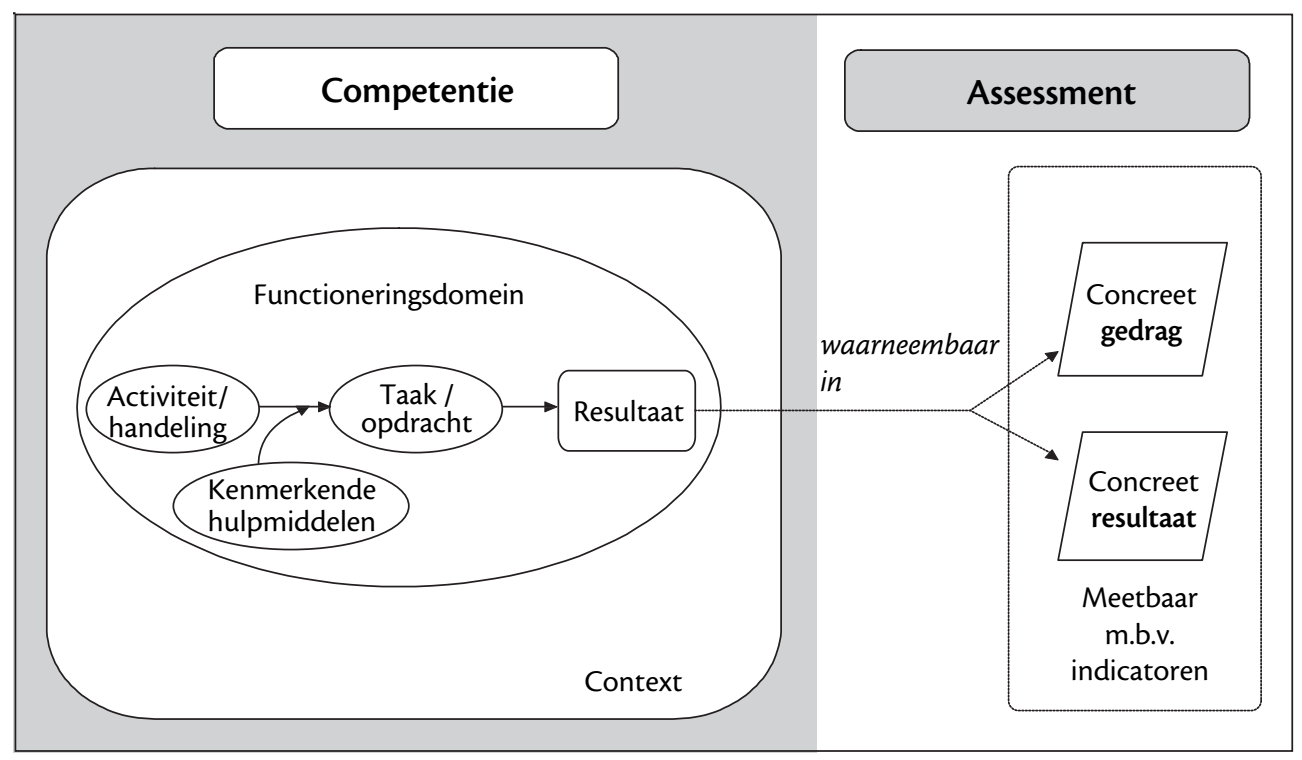

Figuur 1. Competentie en assessment. 
nieuwe eisen uit de omgeving vraagt persoonlijke bekwaamheden.

\section{Toets}

In onderwijsland kan het begrip 'toets' gedefinieerd worden conform Van Berkel en Bax:9 "Elk instrument dat een onderwijsinstelling hanteert bij het nemen van beslissingen over de kennis en vaardigheden, bij een student." In die zin is toetsen een onlosmakelijk onderdeel van leren en onderwijzen. Bij CGO betekent dit dat eerst de kenmerkende en kritieke werkprestaties van het beroep gedefinieerd moeten worden, die daarna ontleed moeten worden in competenties. Vervolgens moet het competentieprofiel in kaart worden gebracht door middel van toetsen (in dit specifieke geval 'assessment' genoemd). $\mathrm{Bij}$ het beoordelen van competenties gaat het om het bepalen van de mate waarin een competentie verworven is. Op een bepaald moment wordt bij een student een beslissing genomen. Hij moet op dat moment een bepaald niveau in zijn competentieontwikkeling hebben behaald en voldoende competent handelen naar dat niveau.

\section{Assessment}

Onder assessment wordt verstaan de beoordeling van gedrag en de resultaten daarvan aan de hand van een realistische praktijktaak. ${ }^{1}$ Grofweg worden vier vormen van assessment onderscheiden (tabel 1): $:^{1,10}$

- Self-assessment (student reflecteert op het functioneren in de taak).
- Peer-assessment (collega's geven feedback op iemands functioneren).

- Expert-assessment (expert observeert gedrag en beoordeelt het gedrag van de student en het behaalde resultaat).

- Portfolio-assessment (docent beoordeelt lerend vermogen met betrekking tot de geformuleerde competenties op basis van een portfolio met bewijsstukken (resultaten) door de student samengesteld). Het portfolio heeft verschillende doelen. Het kan dienen als beoordelingsinstrument, als begeleidingsinstrument en/of als instrument om competentieontwikkeling in kaart te brengen. Wanneer een beoordeling en een cijfer worden gegeven, dient het portfolio als beoordelingsinstrument.

Berkel en Bax $^{9}$ geven aan dat gedrag en de resultaten daarvan in meerdere situaties beoordeeld moeten worden. Dat sluit aan bij de definitie van Kuiper en Lemette. ${ }^{7}$ De meest gebruikte taken zijn de postbakoefening, een tweegesprek, een groepsopdracht, een presentatie en de fact findingopdracht. ${ }^{9}$

\section{Toepassing assessment bij KAG}

De Kenniskring Arbeid en Gezondheid van de Hogeschool Rotterdam heeft eerst competenties van de professional met de differentiatie Arbeid en Gezondheid (A\&G) geformuleerd en in tweede instantie het betreffende onderwijs en de daarbij behorende assessments ontwikkeld. In de onderstaande paragrafen wordt ingegaan op de competenties, uitgangspunten voor

Tabel 1. Assessmentvormen en karakteristieken.

\begin{tabular}{lllll}
\hline & Self-assessment & Peer-assessment & Expert-assessment & Portfolio-assessment \\
\hline Beoordelaar & Student & Collega's & Expert & Docent \\
Aspect & Gedrag en resultaat & Gedrag en resultaat & Gedrag en resultaat & Resultaat \\
Tijdspad & Periode & Periode & Moment & Periode \\
\hline
\end{tabular}


het assessment en de vormgeving van het assessment.

\section{Competenties}

De te verwerven competenties zijn breed geformuleerd, zodat er ruimte bleef om hieraan per opleiding specifieke beroepscompetenties toe te voegen. De context is echter wel toegespitst op arbeid en gezondheid, zodat afgestudeerden zich na het volgen van deze differentiatie kunnen onderscheiden van andere studenten.

Het competentiegebied A\&G bestond uit drie domeinen: zorg (incl. training en advies), organisatie en beroep. De drie domeinen zijn verder uitgesplitst in een zestal domeinspecificaties met bijbehorende kerncompetenties.

Voor elk competentiegebied is een aantal rollen benoemd die een beroepsbeoefenaar met een A\&G-differentiatie kan vervullen. De rollen bij een A\&G-differentiatie zijn die van zorgverlener, adviseur, coach en beroepsbeoefenaar. In een relevante context zou een student na het vol- gen van de A\&G-differentiatie effectiever en efficiënter moeten kunnen handelen dan iemand zonder deze differentiatie.

\section{Vooronderstellingen bij het beoordelen}

Uitgangspunten bij het beoordelen zijn de door de KAG geformuleerde competenties en een multidisciplinaire setting. Er is gekozen voor een expert-assessment en een portfolio-assessment, omdat deze assessmentvormen lijken te passen bij de te verwerven competenties. De vooronderstelling is dat een combinatie van assessmentvormen zich leent voor een valide beoordeling van de betreffende competentie(s), waarbij kennis, visie, houding en vaardigheden zijn geïntegreerd. Aangenomen is dat het portfolio-assessment een procesgerichte benadering geeft (en daarom een weerslag is van een periode waarin de student zelf de bewijslast verzamelt en presenteert) en een expert-assessment juist een momentopname is. In een portfolioassessment worden derhalve gemakkelijk structurerende en schrijfvaardigheden

Tabel 2. Voorbeeld competentiebeschrijving Arbeid en Gezondheid.

\section{Rol}

Domein

Domeinspecificatie Kerncompetentie

\section{Gaat het om}

Zodat
Begeleider.

Zorg voor individu en organisatie.

Vraaggerichte begeleiding van individu en organisatie.

Om de last van (arbeidsgerelateerde) stoornissen en/of beperkingen te verlichten, biedt de beroepsbeoefenaar op professioneel verantwoorde wijze (multidisciplinaire) zorg, training of advies aan individu(en) en organisatie(s) aan.

Het verlenen van zorg voor individu en organisatie door een hbo-er.

Rekening houden met de mogelijkheden van het individu of de organisatie.

- Arbeidsbelasting inschatten.

- Aangeven welke mogelijkheden en beperkingen een risico-inventarisatie en -evaluatie bieden.

- Enkele risico-inventarisatie- en evaluatie-instrumenten toepassen.

- Gegevens over ziekteverzuim verzamelen en interpreteren.

- Een reïntegratieplan beoordelen.

- Aangeven wat de relatie is tussen arbeid en gezondheid, gezien vanuit de rol van begeleider.

Verzuim systematisch voorkomen, of beperken. 
overgewaardeerd, terwijl in het expert-assessment gemakkelijk inlevingsvermogen, charisma, flexibiliteit en klinisch redeneren worden overgewaardeerd. Omdat beide assessments ontworpen zijn om dezelfde competenties te beoordelen, geeft de combinatie van assessments een completer beeld (moment en proces, weerslag van het handelen, het actuele handelen en klinisch redeneren, en een intersubjectief beeld). Beoordeeld wordt of de student de competenties verworven heeft (zie figuur 1). Het assessment is gericht op:

- Het beoordelen van gedrag waaruit blijkt dat de competenties behaald zijn (het expert-assessment).

- Een evaluerend gesprek naar aanleiding van een (reflectie-)verslag waaruit blijkt dat de student zijn leerproces en werkwijze kan verantwoorden naar proces en resultaat (het portfolio-assessment en het expert-assessment).

De assessmentopdrachten zijn te vergelijken met de wijze waarop het onderwijs is aangeboden. Tijdens de studie hebben studenten voldoende gelegenheid voor oefening en terugkoppeling aangeboden gekregen om het assessment te kunnen afleggen.

Beoordelaars zijn ter zake kundige docenten en externen. Voor het assessment gold dat deze docenten niet bij de begeleiding van de betreffende (groep) studenten waren betrokken.

\section{Beschrijving van de assessments}

Bij beide vormen van assessment is uitgegaan van de volgende randvoorwaarden:

- De opleiding heeft een competentieprofiel, bekend bij docenten en studenten (zie competenties).

- De student heeft aan de hand van het competentieprofiel een persoonlijke competentiekaart samengesteld, waarin de competenties stonden aangegeven die hij op dat moment bezit (portfolio).
- De opleiding biedt mogelijkheden de competenties te verwerven door onderwijs aan te bieden.

- De student heeft een begin gemaakt met het vullen van zijn portfolio met bewijslast voor de competenties die hij op dat moment beheerst.

\section{Portfolio-assessment}

Het portfolio biedt de student de mogelijkheid om zijn of haar vorderingen te bewijzen. Het principe van het portfolio is het BeReNPLAN-model (figuur 2): Bewijs verzamelen, Reflecteren, Niveau van functioneren en ontwikkelingsPLAN opstellen. Het Bewijs bestaat uit de opdrachten en werkstukken én de feedback van docenten en eventueel medestudenten op het werk. Daarna wordt de student geacht te Reflecteren. Aan de hand van deze reflectie bepaalt de student het eigen Niveau van functioneren. Hierbij werd het competentieprofiel van de KAG betrokken. Aan de hand daarvan wordt een ontwikkelingsPLAN opgesteld. Vervolgens begint de cyclus opnieuw.

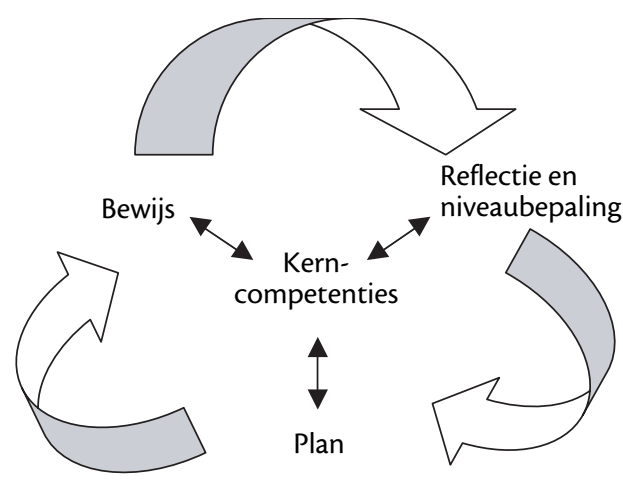

Figuur 2. BeReNPLAN-model.

Voorafgaand aan het portfolio-assessment toetst een docent of de portfolio compleet is (dat wil zeggen of alle verplichte onderdelen opgenomen zijn in het portfolio: re- 
sultaten van opdrachten, self-assessment en peer-assessment, reflectie en ontwikkelingsplan). In het portfolio-assessment beoordeelt de docent of de student voldoende kan bewijzen dat de student de competenties heeft verworven in de voorafgaande periode. De beoordeling resulteert in een cijfer op een schaal van 1-10.

\section{Expert-assessment}

De studenten ontvangen een realistische beroepsopdracht. De studenten (van verschillende opleidingen) vormen een reintegratiebureau. Elk persoon vindt aan het begin van zijn werkdag verschillende mededelingen in zijn postvak. De inhoud van het postvak bevat aanwijzingen over de opdrachten en afspraken die de student die dag moet vervullen. Een voorbeeld van de gespreksnotities kan bijvoorbeeld een door de secretaresse gemaakte afspraak met een cliënt (tweegesprek) zijn: de afspraak betreft een uitnodiging voor een sociaal medisch team (SMT), met de opdracht een presentatie te houden over de mogelijkheden voor een reïntegratietraject voor de betreffende werknemer.

De hele opdracht is te zien als een fact finding-opdracht die moet resulteren in een analyse en een presentatie van oplossingsalternatieven. Interprofessioneel samenwerken is in dit geval een voorwaarde om de opdracht tot een goed einde te brengen.

De beoordelaars (cliënt, leden van het SMT) stellen vast in welke mate de studenten de competenties beheersen. Het assessment wordt afgesloten met $15 \mathrm{mi}$ nuten reflectie op zowel het gedrag als de resultaten van de dag. Zowel het beroepsmatig handelen (gedrag en resultaat) als het klinisch redeneren en het gebruik van evidence worden beoordeeld. De beoordeling resulteert in een cijfer op een schaal van $1-10$.

\section{Beschouwing}

De cruciale vraag is welke assessmentvormen geschikt zijn voor het beoordelen van competenties. Luken ${ }^{11}$ pleit voor het begrip 'beoordelen' in plaats van 'meten', omdat dat recht doet aan het feit dat competenties niet meetbaar, maar wel beoordeelbaar zijn. In zijn betoog noemt hij acht argumenten. In het eerste argument wordt aangegeven dat competentie geen homogeen begrip is. Een competentie bestaat namelijk uit verschillende items (kennis, houding, vaardigheden), waardoor de interne samenhang ontbreekt en deze per definitie niet te meten is. Elshout-Mohr en Oostdam ${ }^{12}$ stellen dat het totaaloordeel over een competentie een gewogen som is van scores op afzonderlijke maatstaven.

Luken ${ }^{11}$ vermeldt ook de subtiele manier waarop resultaten soms tot stand komen. Met slechte elementen wordt soms toch efficiënt een goed resultaat geboekt en vice versa.

Door het feit dat competenties niet echt te meten zijn, heeft het weinig nut om harde beoordelingsmaten te hanteren. Dit kan een nadeel zijn, omdat hierdoor de beoordeling subjectiever wordt. Dit pleit voor meerdere vormen van beoordeling met meerdere mensen. Ook in de literatuur wordt aangegeven dat gedrag en de resultaten daarvan in meerdere situaties beoordeeld moeten worden.

Het portfolio-assessment wordt (in de differentiatie van de KAG) door één assessor beoordeeld. Het expert-assessment wordt door twee assessoren beoordeeld die expert op hun vakgebied zijn. Doordat de inhoud van het portfolio zeer divers is, is de beoordelaar per definitie geen expert op alle terreinen. Mede door het ontbreken van een tweede assessor is de kans op een 'gekleurde' beoordeling groter, waardoor er meer variatie in cijfers kan ontstaan. 
Ofschoon er nog geen 'harde' resultaten beschikbaar zijn, is de eerste indruk dat de combinatie van zowel portfolio als het assessment door de studenten en de beoordelaars als prettig wordt ervaren. Gesteund door resultaten uit de literatuur pleit dit voor beoordeling van concreet gedrag in combinatie met een concreet resultaat. Hiervoor lijkt de combinatie van een portfolio-assessment en een (expert-)assessment een goede methode te zijn. Toch kunnen bij de door ons gekozen methode ook kanttekeningen geplaatst worden.

\section{Assessmentconstructie}

De KAG is gestart met het beschrijven van de competenties en de inhoud van de leertaken (modules). Daarna is er een assessmentvorm bedacht. Achteraf zou het beter geweest zijn het proces om te draaien, omdat:

1. de leertaken de student dan beter in staat stellen de competenties te verwerven;

2. het expert-assessment en het portfolioassessment dan ook daadwerkelijk de gewenste competenties beoordelen.

Ideaal zou zijn:

- Stap 1: competenties formuleren. Op te leveren producten en handelingen te bedenken en hiervoor product- en handelingscriteria te formuleren.

- Stap 2: de assessmentvormen ontwerpen (bijv. expert-assessment en portfolio-assessment). Wat moet het assessment opleveren aan producten en handelingen en aan welke criteria moeten deze voldoen.

- Stap 3: uitgaande van het assessment een leertaak of route ontwerpen die het mogelijk maakt dat de student de competenties verwerft. De leertaak zou leidend moeten zijn.

\section{Actuele performance}

Een groot voordeel van assessment aan het eind van een periode is het integratieve karakter. Een nadeel kan zijn dat studenten zich er bij het onderwijs makkelijk van af maken, doordat er geen tussentijdse assessments bestaan die een deel van de lesstof afsluiten. Doordat de beoordeling van de competentieontwikkeling laat plaatsvindt, bestaat de kans dat er onvoldoende sturing en feedback op het leerproces is. Er ontstaat een alles of niets situatie. Zo kan het zijn dat het portfolio een aantal ontwikkelingen van de student vraagt (en documentatie daarvan) die aan het eind wel of niet blijken te zijn doorlopen. Een mogelijke oplossing zou een diagnostische toets kunnen zijn. Hierbij wordt gekeken in hoeverre een bepaalde competentie (maar ook gewoon 'platte' theoretische kennis) is ontwikkeld op een bepaald moment (bijvoorbeeld halverwege een periode). Dit kan op vrijwillige of verplichte basis. Op verplichte basis kan het gebruikt worden om groen licht te geven voor toelating tot een assessment. Dus: een go-no-go karakter, zonder er studiepunten of credits aan te koppelen. Dit sluit ook aan bij het idee dat een assessment meer is dan een eenzijdige beoordeling op basis van goed gedefinieerde psychometrische criteria. Zo kan een assessment een belangrijke 'lesvorm' zijn, waarbij de student en assessor samen zowel het resultaat als het proces bekijken en bedenken hoe het de volgende keer beter kan. ${ }^{13}$

\section{Assessoren}

Tijdens het assessment van de KAG bleek dat niet alleen de studenten, maar ook de assessoren behoefte hebben om onderling te overleggen en te reflecteren op eigen handelen. Assessoren kunnen hun werk niet in een 'steriel vacuüm' uitvoeren, waardoor er altijd contextuele aspecten meespelen. ${ }^{14}$ Het is daarom van groot belang voldoende ruimte en tijd te plannen 
tussen de studenten, maar ook tussen assessment en de beoordeling/feedback.

\section{Portfolio}

Het gebruik van een portfolio als assessmentinstrument kent zowel voor- als nadelen. Door de assessoren van de KAG werden de volgende punten genoemd:

\section{Voordeel}

- Geen piekmoment voor de student. Producten kunnen in alle rust thuis worden gemaakt.

- Weinig nakijkwerk voor de docent.

\section{Nadeel}

- Er kan een piekbelasting voor de docent ontstaan.

- De beoordelaar moet inhoudelijk veel kennis bezitten of er moeten zeer goede productcriteria, vaardigheidscriteria en gedragscriteria zijn gedefinieerd. Een optie zou het werken met meerdere docenten en/of studenten zijn, om te beoordelen.

\section{Tot slot}

Via internet zijn diverse documenten beschikbaar die kunnen helpen bij de praktische inrichting van toetsen binnen competentiegericht onderwijs. Een mooi voorbeeld is te vinden op de website van de Digitale Universiteit. ${ }^{15}$

\section{Literatuur}

1. Berkel A van, Hofman K, Kinkhorst G, Lintelo L te. Competentie-assessment. De ontwikkeling en toepassing van self-, peer- en expert-assessments in het HBO: een praktijkvoorbeeld. Utrecht: Lemma; 2003.

2. Balm M. Beroepscompetenties van paramedici. In: Kuiper C, Balm M, editors. Paramedisch handelen. Het ontwikkelen van beroepsattitudes. Utrecht: Lemma; 2001.

3. Nedermeijer J, Pilot A. Beroepscompetenties en academische vorming in het hoger onderwijs. Hoger onderwijs reeks. Groningen: Wolters-Noordhoff; 2000.
4. Wijnen WHFW. Heeft het onderwijs het begrip competentie nodig? Workshop 14 februari 2001. Eindhoven: Studiecentrum voor Bedrijf en Overheid; 2001.

5. Kessels JWM. Van een leerstofgericht naar een competentiegericht curriculum. Lezing 14 februari 2001. Eindhoven: Studiecentrum voor Bedrijf en Overheid; 2001.

6. Pool A, Pool-Tromp C, Veltman-van Vugt F, Vogel S. Met het oog op de toekomst. Beroepscompetenties voor HBO-verpleegkundigen. Utrecht: NIZW; 2001.

7. Kuiper C, Lemette M. De ergotherapeut als adviseur: identiteit en beroepscompetenties. In: Heijsman A, Kuiper C, Lemette M, editors. De ergotherapeut als adviseur. Methodiek en adviesvaardigheden. Utrecht: Lemma; 1999.

8. Jansen P, Weisfelt M. Competentieprofilering. Concepten en een toepassing bij aankomend registeraccountants. In: Buskermolen F, Parra B de la, Slotman R. Het belang van competenties in organisaties. Utrecht: Lemma; 1999.

9. Berkel H van, Bax A. Toetsen in het hoger onderwijs. Houten: Bohn Stafleu van Loghum; 2002.

10. Challis M. AMEE Medical Education Guide No.11 (revised): Portfolio-based learning and assessment in medical education. Med Teach 1999;21:370-86.

11. Luken T. Zijn competenties meetbaar. Dilemma en uitweg bij het werkbaar maken van het competentiebegrip. Tijdschrift voor Hoger Onderwijs 2004;22:39-53.

12. Elshout-Mohr M, Oostdam R. Assessment van competenties in een dynamisch curriculum. Amsterdam: SCO-Kohnstamm Instituut; 2001.

13. Dochy F. A new assessment era: different needs, new challenges. Learning and Instruction 2001; 10:11-20.

14. Murphy KR, Cleveland JN. Understanding performance appraisal: social, organizational and goalbased perspectives. Thousand Oaks CA: Sage; 1995.

15. Digitale Universiteit. Toetsplanontwikkeling in competentiegericht onderwijs [homepage op internet]. Eindhoven: Fontys Hogescholen; 2005 [geciteerd 4 maart 2005]. Beschikbaar op: http:// www.du.nl/toetsplan.

De auteurs:

Drs. C.H.Z. Kuiper is lector aan de Kenniskring Arbeid en Gezondheid, Hogeschool Rotterdam.

Dr. J.A.J. Borghouts is fysiotherapeut, bewegingswetenschapper en onderzoeker aan de Kenniskring Arbeid en Gezondheid, Hogeschool Rotterdam.

Correspondentieadres:

Dr. C.H.Z. Kuiper, Kenniskring Arbeid en Gezondheid, Hogeschool Rotterdam, Postbus 25035, 3001 HA Rotterdam, tel: 010-2414371, fax: 010-2415159, arbeid. en.gezondheid@hro.nl. 


\section{Summary}

Introduction: The objective of this article is to present the implementation of different assessment formats in competency-based education.

Method: The assessment formats were used to test students in higher education who were working towards a bachelor's degree in a variety of subjects and whose minor subject was 'occupation and health'. The literature shows that behaviour and the consequences of behaviour (results) are best assessed in a variety of situations. Expert assessment and portfolio assessment were used, because they appear to be the most appropriate formats for assessing competencies.

Discussion: Although there is as yet no "hard" evidence, first impressions suggest that the combination of expert assessment and portfolio assessment meets with approval from students and assessors. This suggests that a combination of expert assessment and portfolio assessment may be the preferred assessment format for competency-based education. (Kuiper CHZ, Borghouts JAJ. Interprofessional assessment, is it accurate? Dutch Journal of Medical Education 2005;24(3):138-146.) 